\title{
A CARTOGRAFIA DO RELEVO COMO SUBSÍDIO PARA A ANÁLISE MORFOGENÉTICA DE SETOR CUESTIFORME
}

\author{
the relief's cartography as subsidy for the morphogenetic \\ analysis of cuestiform sector
}

\author{
Cenira Maria Lupinacci da Cunha* \\ Leandro Godoi Pinton**
}

\begin{abstract}
Resumo
Esse artigo avaliou como a cartografia das feições morfográficas e morfométricas do relevo podem auxiliar na discussão da morfogênese. Para tanto se discute a hipótese de que o mapeamento dos dados morfográficos indica feições de relevo cujos processos de esculturação não são passíveis de serem cartografados, porém são identificáveis através da dedução e de investigações "in loco". Os dados morfométricos indicam potencialidades ao desenvolvimento dos processos morfogenéticos. A correlação desses dados possibilita levantar hipóteses consistentes sobre a morfogênese da área. Assim, utilizando-se dos princípios da Teoria Geral dos Sistemas como orientação metodológica, avaliou-se a morfometria, através da construção de uma carta de energia do relevo, e a morfografia, através da elaboração da carta geomorfológica a partir da técnica de autor clássico. A área de estudo constituiu-se na bacia hidrográfica do Córrego do Cavalheiro - Analândia/SP. Os dados obtidos com os documentos cartográficos, associados aqueles de campo, permitiram o entendimento das relações espaciais entre as formas de relevo, a qual é importante para a análise morfogenética.
\end{abstract}

Palavras-chave: Morfometria Mmorfografia, Cartografia do relevo, Setor cuestiforme.

\begin{abstract}
The objective from this article is to evaluate how the cartographic of the relief's morphografics and morphometrics features can help the discussion of the morphogenesis. For so, the hypothesis of the mapping from the morphagrafics' data indicate relief's features whose sculpturion's process aren't susceptible to be cartographed, however it is identifiable through the deduction and "in locus" investigations is discussed. Whereas the morphometrics' data indicates potentialities to the development of the morphogenetics processes. Therefore, the correlation between these data makes it possible to raise solid hypotheses about the morphogenesis of determined area. In this way, using the principles of the General Systems Theory as methodological guidance, the morphometry was valuated through the elaboration of a relief's energy map, and the morphography, though the elaboration of the geomorphology's map starting from classic's author technical guidance. The Cavalheiro hydrographic basin - Analândia/SP. The obtained data with the cartografics documents, associated with those from field, allowed the understanding of the space relations among the relief's forms, which one is important for the morphogenetic analysis.
\end{abstract}

Key words: Morphometry, Morphography, Relief's cartography.

\begin{abstract}
Resumen
Este artículo examina cómo la cartografía de las características morfográficas y morfométricas del relieve pueden ayudar en la discusión de la morfogénesis. Con este fin se discute la hipótesis de que el mapeo de los datos morfográficos indican características del relieve cuyos procesos de esculturación no son probables de ser cartografiados, pero son identificables a través de la deducción y la investigación "in situ". Los datos morfométricos indican potencialidades al desarrollo de los procesos morfogenéticos. La correlación de estos datos permite formular hipótesis consistentes sobre la morfogénesis del área. Así, utilizando los principios de la Teoría General de Sistemas como orientación metodológica, se evaluó la morfometría, mediante la construcción de una carta de energía de relieve, y lo morfografía, a través de la elaboración de una carta geomorfológica a partir de una técnica de autor clásico. El área de estudio consistió en la Cuenca hidrográfica de Córrego do Cavalheiro (Arroyo del Caballero) - Analândia/SP. Los datos obtenidos con los documentos cartográficos relacionados con los del campo, permitieron la comprensión de las relaciones espaciales entre las formas del relieve, lo cual es importante para el análisis morfogenético. Por lo tanto, se consideró que la cartografía del relieve es una herramienta importante para el análisis morfogenético.
\end{abstract}

Palabras-clave: Morfología, Morfografía, Mapas en relieve, Sector cuestiforme.

(*) Prof. Dra. do Departamento de Planejamento Territorial e Geoprocessamento - Laboratório de Geomorfologia - UNESP Campus de Rio Claro. Av. 24A n. 1515 Bela Vista - Rio Claro (SP), Brasil. Tel. (+55 19) 3526-9331 - e-mail: cenira@rc.unesp.br

$(* *)$ Doutorando em Geografia pela Universidade Estadual de São Paulo - Rio Claro - Laboratório de Geomorfologia - UNESP - Campus de Rio Claro. Av. 24A n. 1515 Bela Vista - Rio Claro (SP), Brasil. Tel. (+ 55 19) 3526-9331 - lgpgeo@rc.unesp.br 
CUNHA, C. M. L.; PINTON, L. G.

\section{INTRODUÇÃO}

A geomorfologia, entendida como o estudo das formas de relevo e dos processos responsáveis por sua elaboração, tem na cartografia geomorfológica um dos mais importantes veículos de comunicação e análise dos resultados obtidos.

Entretanto, a cartografia geomorfológica constitui-se em um tipo de mapeamento cuja complexidade é inerente ao próprio objeto de representação. O relevo apresenta uma diversidade de formas e de gênese, as quais são geradas por complicados mecanismos que atuam no presente e que atuaram no passado. Em relação aos referidos mecanismos, destaca-se as características climáticas reinantes, que implicam na ação física e química dos agentes atmosféricos no processo de esculturação do relevo. Assim, em áreas com clima árido, semi-árido e em ambientes glaciais e periglaciais, a meteorização física é mais significativa que a ação química. Já nos ambientes quentes e úmidos, a ação química da água e do calor é mais significativa na morfogênese do relevo. Desse modo, uma cartografia geomorfológica eficiente deve fornecer subsídios para a identificação de todos os elementos essenciais para o entendimento do relevo.

De acordo com Fairbridge (1968), um mapa geomorfológico, para ser considerado completo, deve fornecer informações sobre a forma (morfografia), as dimensões (morfometria), a origem (morfogênese) e a idade (morfocronologia) de cada elemento do relevo. A concepção deste autor é compartilhada por autores brasileiros, como Ross (1991), entre outros, embora existam muitas dificuldades no que se refere à legibilidade de documentos cartográficos que trazem este tipo de configuração. Assim, Ross (1991, pg. 55) afirma que “[...] fica claro que os geomorfólogos em geral são unânimes quanto à questão do conteúdo geral dos mapas [...] os mapas devem informar sobre os tipos de formas de relevo, gênese e idade".

Nesse contexto, esse artigo tem como objetivo avaliar como a cartografia das feições morfográficas e morfométricas do relevo pode auxiliar na discussão da morfogênese de um setor cuestiforme em ambiente quente e úmido. Para tanto se discute a hipótese de que o mapeamento dos dados morfográficos indica feições de relevo cujos processos de esculturação não são passíveis de serem cartografados, porém são identificáveis através da dedução e de investigações “in loco". Já os dados morfométricos indicam potencialidades ao desenvolvimento dos processos morfogenéticos. Dessa forma, a correlação destes dados possibilita levantar hipóteses consistentes sobre a morfogênese de determinada área.

Os dados morfométricos foram avaliados através da elaboração da carta de energia do relevo segundo a proposta de Mendes (1993). Tal documento cartográfico avalia qualitativamente, por meio de uma síntese, os dados obtidos com as cartas de declividade, de dissecação horizontal e de dissecação vertical. Já o mapeamento geomorfológico, com ênfase aos dados morfográficos, seguiu os princípios propostos por Tricart (1965), nos quais a cartografia geomorfológica de detalhe deve apresentar as relações espaciais que as formas de relevo mantêm com os processos de esculturação e/ou de elaboração do modelado.

Para testar a hipótese mencionada selecionou-se como área de estudo a bacia do Córrego do Cavalheiro, situada em Analândia (SP). A escolha dessa área deve-se à complexidade geomorfológica e morfogenética da mesma. Tal complexidade relaciona-se ao fato dessa estar na transição de dois compartimentos geomorfológicos do Estado de São Paulo - Depressão Periférica Paulista e Cuestas Arenito-Basálticas. As formas de relevo pertencentes a tais compartimentos sofreram um conjunto de processos denudacionais relacionados a circundesnudação, de idade pós-cretácea, dinamizada por eventos tectônicos vinculados a epirogênese terciária da borda da bacia sedimentar do Paraná.

Ressalta-se que as escarpas das linhas de cuestas identificadas na área de estudo são desdobradas, implicando em considerável desnível topográfico, o qual, acrescido de um clima úmido auxilia na regulação da dinâmica fluvial e pluvio erosiva local.

A bacia hidrográfica do Córrego do Cavalheiro localiza-se no setor centro-leste do Estado de São Paulo, no município de Analândia, entre as coordenadas geográficas de $22^{\circ} 05^{\prime} 36^{\prime \prime}$ e 22 $07^{\circ}$ '58 " 


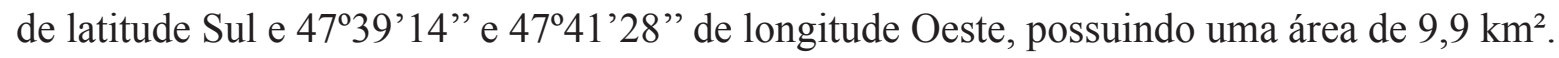

Convêm salientar que a bacia do Córrego do Cavalheiro constitui-se em uma das áreas de nascentes do rio Corumbataí, o qual possui grande importância regional devido ao seu potencial hídrico para abastecimento dos municípios de Analândia, Corumbataí, Rio Claro e Piracicaba.

\section{PROCEDIMENTOS METODOLÓGICOS E TÉCNICOS}

A análise dos dados obtidos para a bacia do Córrego Cavalheiro foi efetuada considerando-se os princípios que norteiam a Teoria Geral dos Sistemas. Dentre esses princípios, enfatiza-se a questão da composição, funcionalidade e estrutura do sistema geomorfológico.

Em relação à composição dos sistemas, nos estudos de Geomorfologia, considera-se que, para compreender a morfogênese do relevo, devem-se analisar os fluxos de matéria e energia, bem como a estruturação do mesmo, ou seja, as relações entre os seus elementos. Deste modo, por meio da Teoria Geral dos Sistemas é possível estabelecer e analisar as inter-relações inerentes à morfogênese do relevo.

No que se refere a questão funcional, devido o presente estudo utilizar como objeto de pesquisa a bacia hidrográfica do Córrego do Cavalheiro, encontra-se, por meio dessa, a justificativa para a utilização da Teoria Geral dos Sistemas já que a bacia hidrográfica pode ser entendida como um sistema aberto.

Para o critério da complexidade estrutural, esse estudo utilizou-se da concepção dos sistemas morfológicos e dos sistemas processos-respostas. Assim, foi possível avaliar o caráter morfológico do sistema relevo através da elaboração de documentos cartográficos que viabilizaram medir a geometria desse. Através de procedimentos matemáticos e cartográficos que possibilitaram a elaboração das cartas de declividade, dissecação horizontal e vertical, foi possível quantificar a inclinação das vertentes, a distância e a altitude relativa entre linhas de cumeada e talvegues. Dessa forma, foi analisado como tais aspectos relacionados à geometria do relevo da bacia estudada criam condições potenciais para o desenvolvimento dos processos geomorfológicos através da união dessas cartas na energia do relevo.

Já em relação aos sistemas processos-respostas, a avaliação desse aspecto foi possível por meio da elaboração da carta geomorfológica, a qual proporcionou respaldo às inferências dos processos que dão origem às formas de relevo da área de estudo. Dessa forma, por meio dos dados adquiridos nessa carta, os processos relacionados aos sistemas em sequência foram deduzidos a partir do mapeamento das formas de vertentes e interflúvios, das formas originadas pela ação das águas correntes e do modelado antrópico. Entende-se que tais formas se constituem na resposta aos processos morfogenéticos atuantes sobre a área.

\section{TÉCNICAS CARTOGRÁFICAS}

\section{Carta de Energia do Relevo}

A carta de energia do relevo resulta da compilação das cartas de declividade, dissecação horizontal e vertical. Para a construção da carta de declividade da bacia do Córrego do Cavalheiro utilizou-se a técnica convencional proposta por De Biasi $(1970,1992)$ e as adaptações propostas por Sanchez (1993). As cartas de dissecação horizontal e vertical foram elaboradas a partir da proposta de Spiridonov (1981), assim como da técnica da cartografia digital apresentada por Zacharias (2001). A elaboração da carta de energia do relevo foi desenvolvida segundo a proposta de Mendes (1993), utilizando-se da técnica da cartografia digital apresentada por Mathias (2007) para a confecção desse documento cartográfico.

Segundo a proposta de Mendes (1993), o primeiro passo na elaboração dessa carta é o estabelecimento das classes de energia do relevo, as quais são identificadas por termos qualitativos que variam de muito forte a muito fraco. Nesse documento cartográfico, os tons escuros retratam 
as maiores intensidades da energia do relevo, enquanto que os tons claros indicam as menores intensidades desse fenômeno.

Evidencia-se que cada classe foi estabelecida através de uma série de combinações entre os parâmetros de declividade, de dissecação horizontal e de dissecação vertical, considerando-se ainda, as características morfológicas da área de estudo, bem como a expressão areal de cada classe. Essas combinações são promulgadas em cada linha, de cada classe apresentadas na tabela 1.

Em relação à técnica apresentada por Mathias (2007) para a confecção da carta de energia do relevo, pode-se dizer que, assim como a técnica apresentada por Zacharias (2001) para a elaboração das cartas de dissecação horizontal e vertical, essa também se trata de uma técnica semi-automática, já que permite ao usuário o acompanhamento de todas as etapas. Ademais, a técnica proposta por Mathias (2007) para a elaboração da carta de energia do relevo permitiu um ganho significativo de tempo na construção dessa, bem como um ganho na qualidade gráfica da apresentação do resultado final desse documento cartográfico.

\section{Carta Geomorfológica}

A elaboração da carta geomorfológica da bacia do Córrego do Cavalheiro foi realizada segundo a proposta de Tricart (1965). Para a elaboração dessa carta utilizou-se como fonte de dados pares estereoscópicos de fotografias aéreas do cenário de 2000, na escala 1:30.000, disponíveis para empréstimo na Casa de Agricultura do município de Analândia; mapeamentos geológicos (São Paulo, 1984); e a base topográfica da área de estudo. Evidencia-se ainda que foram realizados trabalhos de campo para a reambulação e atualização dos dados mapeados, bem como para suprir a deficiência de informações causada pela escala das fotografias aéreas. Essas fontes de dados condizem com a proposta de Tricart (1965).

Dessa forma, a primeira etapa para a elaboração da carta geomorfológica da bacia do Córrego do Cavalheiro foi a realização da fotointerpretação, utilizando-se de um estereoscópio de bolso. Nesse procedimento foram obtidas informações referentes à morfometria e morfografia. Essas últimas foram agrupadas de forma a indicar a morfogênese. Nota-se que as informações sobre a cronologia não foram representadas. Esse fato se dá pela falta de informações sobre a mesma da área de estudo. Tricart (1965) salienta ainda que, esse tipo de informação constitui-se no de mais difícil obtenção, assim como no mais complexo e de difícil precisão na cartografia geomorfológica.

As informações referentes à morfometria foram representadas apenas pela rede de drenagem, as linhas de cumeada e o limite da bacia visto que a análise da morfometria da área já havia sido realizada por meio da carta de energia do relevo.

Por fim, a etapa final de elaboração do mapa geomorfológico constituiu-se na edição final do mesmo no programa CorelDraw 12.

\section{ANÁLISE DOS RESULTADOS}

A bacia do Córrego do Cavalheiro é marcada, geomorfologicamente, pela presença de um conjunto de relevos típicos do sistema cuestiforme. Assim, todo o setor norte apresenta feições ligadas à presença de litologias derivadas dos derrames basálticos - Formação Serra Geral - que marcam a Bacia Sedimentar do Paraná. Dessa forma, a carta de energia do relevo (Figura 1) apresenta nesse setor a classe muito forte, o que se deve aos grandes declives derivados do front cuestiforme. Esses declives estão diretamente relacionados à maior resistência litológica desse setor. Dessa forma, essas características morfométricas distinguem esse setor dos demais setores da área de estudo como sendo o de maior potencialidade para o desenvolvimento da dinâmica pluvio erosiva. 
Tabela 1 - Classes de energia do relevo da bacia do Córrego do Cavalheiro

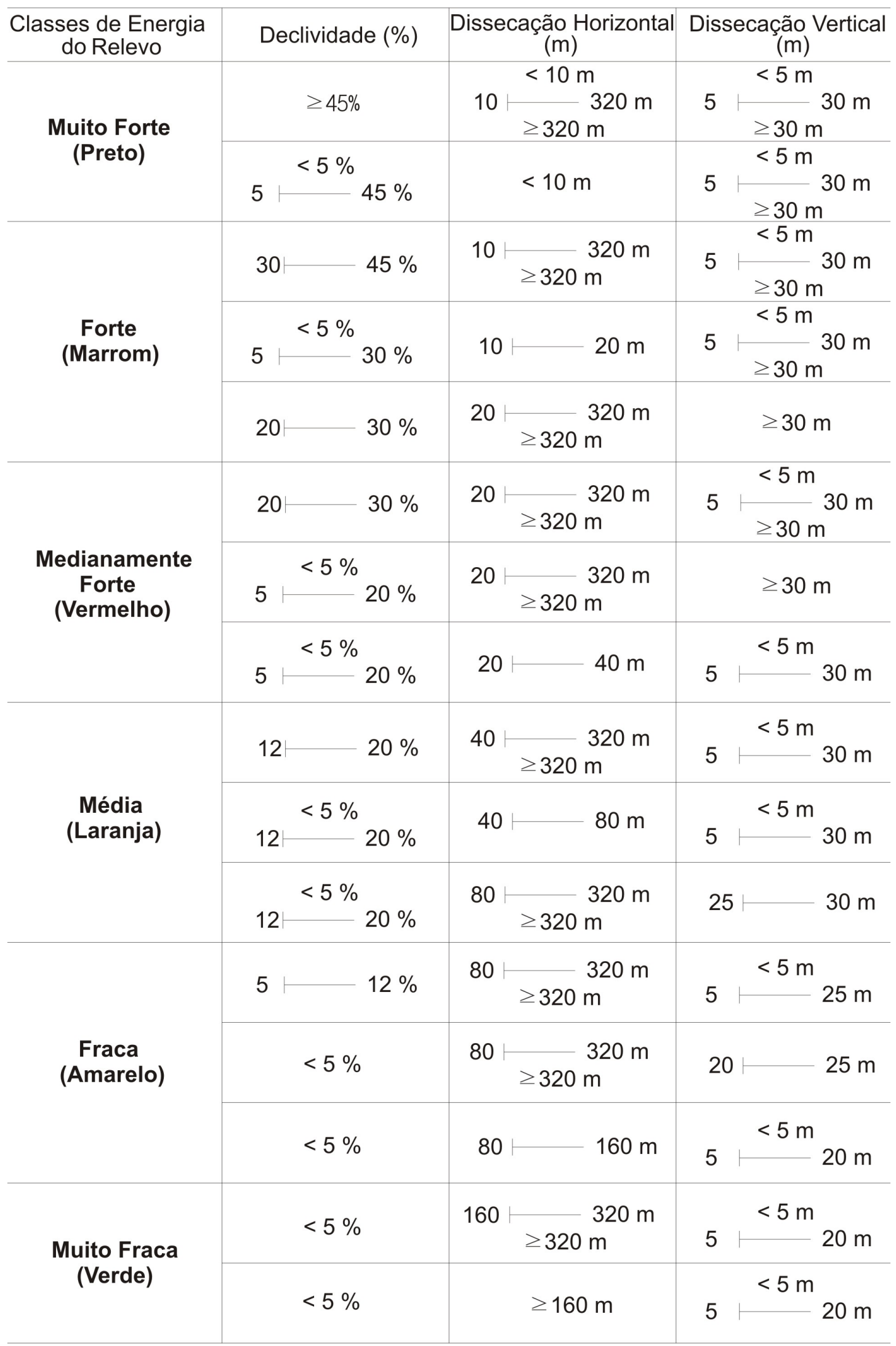




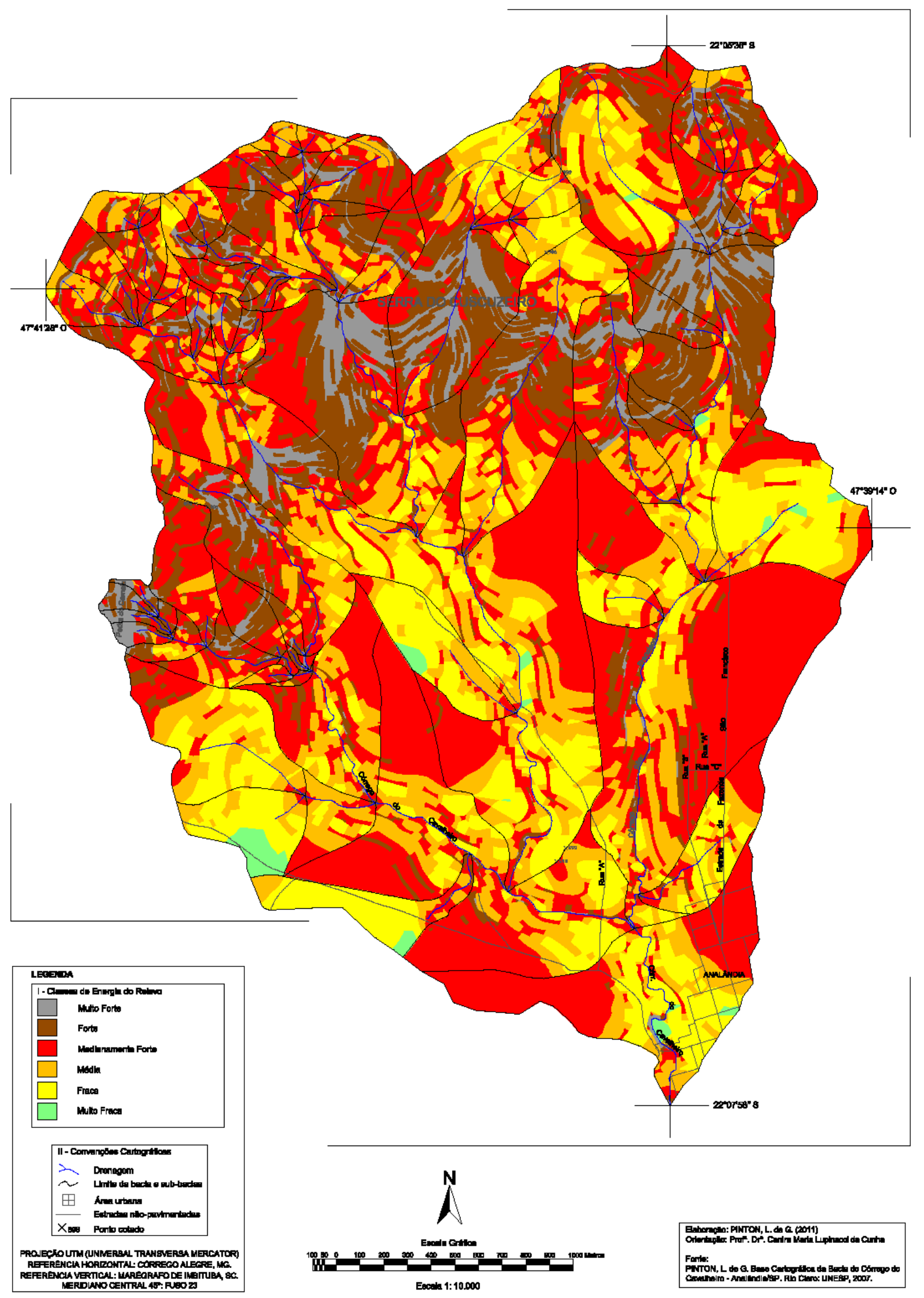

Figura 1 - Carta de energia do relevo da bacia do Córrego do Cavalheiro - Analândia - SP 
A presença da Formação Serra Geral cria ainda um conjunto de formas de relevo complexas que foram mapeadas através da carta geomorfológica (Figura 2). Assim, têm-se dois fronts cuestiformes, caracterizando o desdobramento da cuesta, fato já apontado para outros setores do estado de São Paulo por Ab'Sáber (1998) e, em algumas frentes de cuestas da região Nordeste segundo Ross (2008). Além disso, foram registrados vários patamares estruturais, vinculados a setores onde tal resistência litológica já foi vencida pelos processos denudativos. Essas formas estão cercadas por diversas outras, tais como sulcos erosivos, rupturas topográficas e voçorocas (Figrua 2), que indicam claramente a atuação dos processos erosivos nesse setor. Além dessas feições, a presença de diversos morros testemunhos no setor noroeste indica o processo de recuo cuestiforme, o qual é mais acelerado nessa área devido à energia gerada pela presença de um bloco soerguido. Esse bloco, nitidamente delimitado na carta geomorfológica e visível em campo, cria desnível topográfico significativo, colaborando com a aceleração do escoamento de superfície e com a geração das diversas feições erosivas nesse setor.

Assim, a partir dos dados acima narrados, considera-se que esse setor da bacia do Córrego do Cavalheiro constitui-se naquele onde os processos morfogenéticos atuam mais nitidamente, o que implica em relativa instabilidade dos terrenos apesar da presença de litologias resistentes, como inicialmente mencionado. A discordância erosiva entre essas litologias e os demais terrenos areníticos de entorno, combinada com as características tectônicas do terreno e o clima quente e úmido geram a aceleração da morfogênese.

O extremo norte desse setor da bacia caracteriza-se como o reverso cuestiforme, apresentando litologias areníticas e declives suaves. Apesar disso, a presença de inúmeras nascentes nessa área gera consideráveis índices de dissecação horizontal os quais condicionam energia do relevo (Figura 2) classificada como média a muito forte. Esse setor, mesmo apresentando baixos declives, transiciona com o front cuestiforme e, assim, a erosão fluvial acelera-se nessa transição, gerando cascatas e corredeiras. Tal aceleração tende a remontar tanto no interior das drenagens como em direção as vertentes, fato já amplamente reconhecido na bibliografia sobre morfogênese em ambientes quentes e úmidos. Dessa forma, verifica-se a presença de diversas rupturas topográficas e sulcos erosivos (Figura 3) que apontam para considerável dinâmica denudacional.

Dessa forma, esse extremo norte tem grande importância, já que se constitui no setor de nascentes do Córrego Cavalheiro. Porém, tais nascentes ocorrem em meio a terrenos marcados por feições geomorfológicas que demonstram a aceleração da morfogênese. Tal aceleração é diferente daquela registrada para o setor cuestiforme, caracterizando-se por operar em níveis menores de atuação já que não sofre diretamente os efeitos gerados pela ação tectônica, como indicado anteriormente para o setor cuestiforme. Outro fato importante refere-se à proximidade com o setor cuestiforme. Essa proximidade também é responsável pela aceleração dos processos denudativos, já que o desnível topográfico dessa área dinamiza a erosão fluvial. Essa dinâmica fluvial é registrada também no setor centro sul da área de estudo.

O setor centro sul da bacia do Córrego do Cavalheiro caracteriza-se por energia do relevo (Figura 1) predominantemente medianamente forte, apesar de considerável expressão areal das classes fraca e média. Esse setor integra a província geomorfológica da Depressão Periférica Paulista, caracterizando-se por declives suaves e considerável extensão interfluvial. Apesar disso, a dissecação vertical do relevo é considerável, gerando o predomínio de energia do relevo medianamente forte. Entende-se tal tipo de dissecação como sendo potencializadora dos processos denudativos visto que gera alta carga de energia derivada da ação gravitacional. Dessa forma, se este parâmetro morfométrico combinar-se com outros que representam fragilidade à ação denudacional, como tipo de solo, declive do terreno ou tipo de uso da terra, tais processos irão ser deflagrados. Assim, a presença de colos e rupturas topográficas, assim como de sulcos erosivos, mesmo em áreas com terraços agrícolas (Figura 3), demonstra a atuação dos processos pluvio-erosivos. Além disso, deve-se considerar a energia erosiva das drenagens. Os cursos fluviais que cortam o setor centro sul têm suas 


\section{Carta Geomorfológica da Bacia do Córrego do Cavalheiro - Analândia/SP - Cenário do ano de 2007}
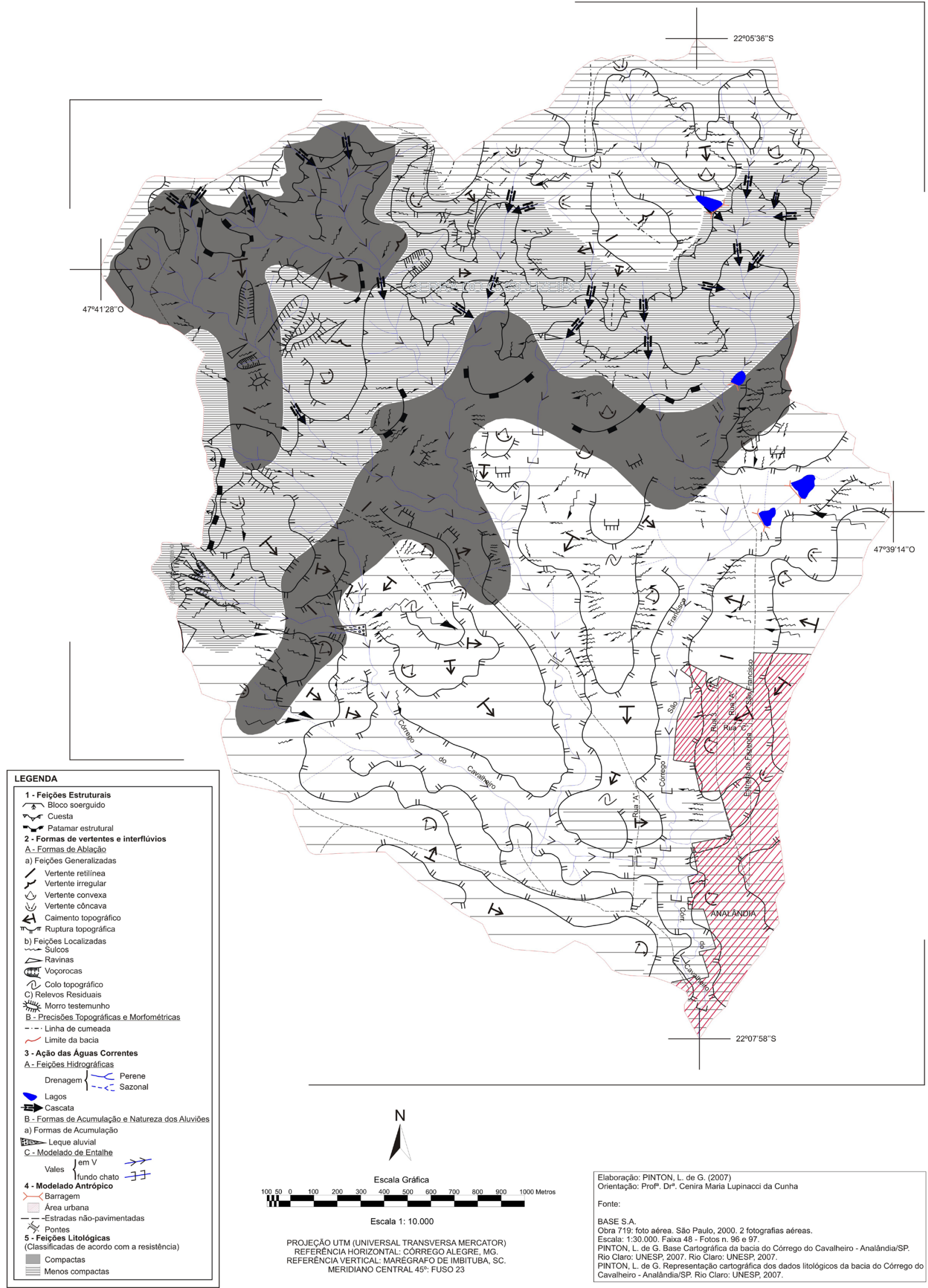

Figura 2 - Carta geomorfológica da bacia do Córrego do Cavalheiro - Analândia - SP 
nascentes em reverso cuestiforme o que gera desnível topográfico significativo ao longo do canal, dando origem a considerável poder erosivo das drenagens. Nesse contexto, o perfil transversal de tais cursos é predominantemente em $\mathrm{V}$, indicando o processo de incisão fluvial. A exceção registra-se no baixo curso do Córrego do Cavalheiro onde ocorrem fundos chatos decorrentes da presença de planícies aluviais (Figura 2). Assim, apesar de se considerar que a dinâmica morfogenética é menor no setor centro sul, existe uma considerável potencialidade para o seu desenvolvimento, a qual se vincula tanto a dissecação vertical do relevo, como a energia das drenagens que é gerada nos setores da alta bacia.

\section{CONSIDERAÇÕES FINAIS}

Os mapeamentos realizados durante a execução desse estudo possibilitaram identificar feições do relevo que indicam a atuação tanto dos processos de esculturação típicos de ambientes quentes e úmidos como de ações tectônicas locais. Assim, considera-se que o mapeamento de tais feições, bem como sua avaliação quantitativa, a partir da morfometria, possibilita levantar considerações importantes sobre a morfogênese da área. Contudo, tais considerações serão efetivamente comprovadas somente a partir da investigação dos materiais de superfície, análise não contemplada nessa pesquisa.

Dessa forma, considera-se que o mapeamento do relevo constitui-se em um dos instrumentos que viabilizam a compreensão da morfogênese principalmente por permitir reconhecer as relações de vizinhança entre as formas, as quais muitas vezes são essenciais para esse tipo de análise. No caso da área investigada, a presença do front cuestiforme dinamiza toda a dinâmica fluvial da área de estudo. Esse fato é importante para o entendimento da morfogênese e possível de ser investigado somente através de uma análise da totalidade da bacia hidrográfica, através da representação cartográfica de seu relevo.

Por fim, considera-se ainda que os dados obtidos fornecem subsídios para o desenvolvimento de pesquisas que consideram a morfogênese em outros setores cuestiformes do Brasil, em especial naqueles que se encontram sob condições climáticas distintas da identificada na área de estudo.

\section{AGRADECIMENTOS}

Pesquisa financiada pela Fundação de Amparo à Pesquisa do Estado de São Paulo - FAPESP - Processo $n^{\circ}$. 06/60616-1.

\section{REFERÊNCIA BIBLIOGRÁFICAS}

AB'SÁBER, A.N. Megageomorfologia do Território Brasileiro. In: GUERRA, A.J.T.; CUNHA, S.B. da (Org.). Geomorfologia do Brasil. Rio de Janeiro: Bertrand Brasil, 1998.

CUNHA, C.M.L. A cartografia do relevo no contexto da gestão ambiental. 2001. $128 \mathrm{f}$. Tese (Doutorado em Geociências e Meio Ambiente) - Instituto de Geociências e Ciências Exatas, Universidade Estadual Paulista, Rio Claro, 2001.

DE BIASI, M. Cartas de declividade: confecção e utilização. Geomorfologia, São Paulo, n. 21, p. 08-12, 1970.

DE BIASI, M. A carta clinográfica: os métodos de representação e sua confecção Revista do Departamento de Geografia, São Paulo, n. 6, p. 45 - 60, 1992.

FAIRBRIDGE, R. W. The encyclopedia of geomorphology. New York: Reinhold Book Corporation, 1968.

MATHIAS, D.T. Técnica de Elaboração da Carta de Energia do Relevo em Meio Digital. In: Congresso de Iniciação Científica, 19, 2007, Araraquara. Resumo Expandido. Araraquara, UNESP, 2007. 
MENDES, I. A. A dinâmica erosiva do escoamento pluvial na Bacia do Córrego Lafon - Araçatuba - SP. 1993. Tese (Doutorado em Geografia Física) - Faculdade de Filosofia, Ciências Humanas e Letras, Universidade de São Paulo, São Paulo, 1993.

ROSS, J. L. S. Geomorfologia: Ambiente e planejamento. São Paulo: Contexto, 1991.

ROSS, J. L. S. Os fundamentos da Geografia da Natureza. In: ROSS, J. L. S (Org.). Geografia do Brasil. São Paulo: USP, 2008. p. 13-65.

SANCHEZ, M.C. A propósito das cartas de declividade. In: SIMPÓSIO DE GEOGRAFIA FÍSICA APLICADA, 5, 1993. São Paulo. Anais... São Paulo, USP, 1993.

SÃO PAULO (Estado). Secretaria de Agricultura e Abastecimento. Coordenadoria da Pesquisa de Recursos Naturais. Folha Geológica de Corumbataí (Folha SF-23-Y-A-I-2): Formações Geológicas de Superfície. São Paulo: Instituto Geológico. Escala 1:50.000. 1984.

SPIRIDONOV, A.I. Princípios de la metodologia de las investigaciones de campo y el mapeo geomorfológico. Havana: Faculdad de Geografia, Universidad de la Havana. 3v, 1981.

TRICART, J. Principes et méthodes de la géomorphologie. Paris: Masson, 1965.

ZACHARIAS, A.A. Metodologias convencionais e digitais para a elaboração de cartas morfométricas do relevo. 2001. 166 f. Dissertação (Mestrado em Geociências e Meio Ambiente) - Instituto de Geociências e Ciências Exatas, Universidade Estadual Paulista, Rio Claro, 2001.

Trabalho enviado em janeiro de 2013

Trabalho aceito em fevereiro de 2013 